\title{
Anxiety and Framing Effects on Decision Making: Insights from Neuroimaging
}

\author{
Marieke Jepma $^{\star}$ and Marina López-Solà \\ Department of Psychology and Neuroscience, University of Colorado Boulder, Boulder, Colorado 80309 \\ Review of Xu et al.
}

Consider the following dilemma: Mary is a power-plant employee who, after years of good job performance, has established an excellent reputation. But, one unfortunate day, Mary makes a mistake that damages an important piece of equipment. Now she can do two things. One option is to immediately report her mistake so that the damage can get repaired quickly and will have minimal consequences. This would definitely harm her reputation, but not so much that she would get fired. Alternatively, Mary can try to fix the damage herself in the hope that her mistake will remain unnoticed. This second option is risky: if she manages to resolve the problem in time she will keep her excellent reputation, but if she does not, the problem will escalate and she will get fired.

What people do when facing a dilemma like this depends on several factors, including their willingness to take risks. Another factor that has been shown to strongly affect these decisions is whether the different options' outcomes are framed in terms of gains or losses. In the example above, Mary's decision may depend on whether her friend, with whom she discusses her dilemma, emphasizes the positive side of reporting her mistake (she will not get fired) or the negative side

Received Dec. 22, 2013; revised Jan. 16, 2014; accepted Jan. 20, 2014. ${ }^{*}$ M.J. and M.L. S. contributed equally to this paper.

Correspondence should be addressed to Marieke Jepma, Department of

Psychology and Neuroscience, University of Colorado Boulder, 345 UCB, Boulder, C0 80309. E-mail: marieke.jepma@colorado.edu.

DOI:10.1523/JNEUROSCI.5352-13.2014

Copyright $\odot 2014$ the authors $\quad 0270-6474 / 14 / 343455-02 \$ 15.00 / 0$ of this same option (her reputation will go down). The phenomenon that people's decisions are biased by the way in which information is presented has been demonstrated in a variety of decision-making situations (Tversky and Kahneman, 1981) and is called the "framing effect."

A few functional magnetic resonance imaging ( $\mathrm{fMRI}$ ) studies have started to investigate the neural mechanisms underlying framing-related decision biases. These studies revealed stronger amygdala activation during decisions that match the frame (i.e., decisions to choose positively framed options and to avoid negatively framed options) than during decisions that run counter to the frame (i.e., decisions to choose negatively framed options and to avoid positively framed options), whereas activation in the anterior cingulate cortex (ACC) and dorsomedial and dorsolateral prefrontal regions showed the opposite effect (De Martino et al., 2006; Roiser et al., 2009). In addition, genetically mediated individual differences in susceptibility to the framing effect were mirrored by differences in activation of the amygdala and its coupling with ACC and medial prefrontal cortex (mPFC; Roiser et al., 2009).

The neural circuitry associated with the framing effect shows a remarkable overlap with that associated with anxiety responses in both healthy and patient populations (Etkin and Wager, 2007; Hartley and Phelps, 2012). Anxiety has been repeatedly associated with enhanced amygdala responses to salient, especially fear-related, emotional cues and with functionally impaired prefrontal-amygdala circuits involved in emotion regulation (Bishop, 2007). A few previous studies have hinted at a relationship between the framing bias and trait anxiety (Lauriola, 2001; Story et al., 2013); a recent study by $\mathrm{Xu}$ and colleagues (2013) directly addressed this issue.

$\mathrm{Xu}$ et al. (2013) examined the framing effect and its associated brain activation as a function of individual differences in trait anxiety. Twenty healthy participants completed an economic decision-making task in which they were repeatedly presented with an initial number of points, corresponding to a certain amount of money, and then had to choose between two options: (1) receive a fixed proportion of these points for sure (e.g., 80 of 100 points; the "safe" option), or (2) gamble, and either win or lose all the initial points (e.g., $80 \%$ chance of winning and $20 \%$ chance of losing all 100 points; the "gamble" option). $\mathrm{Xu}$ et al. (2013) manipulated the framing of the safe option by stating either how many of the initial points would be kept (e.g., "keep 80 points") or how many of these points would be lost (e.g., "lose 20 points") when choosing the safe option.

In line with the framing effect, $\mathrm{Xu}$ et al.'s (2013) participants more often chose the safe option when this option was framed as a gain, but preferred the gamble option when the same safe option was framed as a loss. Importantly, although trait anxiety was unrelated to the overall proportion of gamble decisions, it was positively correlated with the magnitude of the behavioral framing bias (i.e., more 
anxious participants showed a stronger framing effect). As in previous studies, frame-consistent decisions were associated with increased amygdala activation, whereas frame-inconsistent decisions were associated with increased activation in many other brain regions, including the ACC, supplementary motor area, anterior insula, and lateral frontal and parietal regions (Xu et al., 2013, their Fig. $3 A, D$, Table 1). Interestingly, both of these framing-dependent brain-activation patterns were positively correlated with trait anxiety (Xu et al., 2013, their Fig. 3C,F, Table 2). In addition, trait anxiety was positively correlated with the coupling between the amygdala and the ventromedial PFC (vmPFC) during frame-consistent decisions (Xu et al.'s, 2013, their Fig. 4), and negatively with the vmPFC-dorsal ACC coupling during decisions that ran counter to the frame (Xu et al., 2013, their Fig. 5C,F).

$\mathrm{Xu}$ et al.'s (2013) findings provide novel and compelling evidence regarding the relationship between anxiety and the behavioral framing effect on the one hand, and between anxiety and framingeffect-related brain responses on the other. A related important question that remains to be answered is which brain responses during decision making mediate the relationship between trait anxiety and the behavioral framing effect. This question may be addressed using whole-brain mediation analyses (Wager et al., 2008). Mediation analyses explicitly test whether an observed relationship between two variables (a predictor " $\mathrm{X}$ " and an outcome "Y") can be explained by a third explanatory variable (the mediator " $\mathrm{M}$ "). Instead of assuming a direct causal $\mathrm{X}-\mathrm{Y}$ relationship, a mediation model hypothesizes that the predictor variable influences the mediator variable, which in turn influences the outcome variable. Thus, a wholebrain mediation analysis, using each voxel's activation for the framing-effect contrast as possible mediators, may reveal the underlying neural mechanisms by which trait anxiety influences susceptibility to the framing effect.

There are at least two, not mutually exclusive, possible explanations for $\mathrm{Xu}$ et al.'s (2013) finding that the framing effect increases with increasing trait anxiety: (1) anxiety may promote stronger reliance on emotional, rather than probabilistic, information; and (2) anxiety may be associated with reduced cognitive resources, so that making a decision that runs counter to the frame is more effortful for highly anxious individuals. The positive correlation between anxiety and amygdala acti- vation during frame-consistent decisions supports the first explanation, as the amygdala plays a pivotal role in the processing of and response to emotional stimuli. However, it is interesting to note that the correlation between trait anxiety and brain activation during frame-inconsistent decisions seems indicative of an effort-related effect: this activation map (including the ACC, supplementary motor area, anterior insula, and lateral frontal and parietal regions) resembles the activation pattern that is typically observed during cognitively demanding conditions, e.g., in cognitivecontrol paradigms (Crittenden et al., 2012; Power and Petersen, 2013). This supports the idea that for highly anxious individuals it requires more cognitive effort to make decisions that run counter to the frame, rendering them more likely to rely on heuristics such as the use of easily accessible information provided by the framing context. To further dissociate between the two possible explanations mentioned above (the "emotion" and "effort" accounts), it may be helpful to consider participants' reaction times for frameconsistent versus frame-inconsistent decisions, as well as their relationship with anxiety and decision-related brain activation. Specifically, longer reaction times for frame-inconsistent decisions in highly anxious individuals may be indicative of an effort-related effect. We believe that a combination of whole-brain mediation analyses and the study of reaction times is a promising approach to further elucidate the nature of the relationship between trait anxiety and framing-related decision biases.

An interesting open question is whether $\mathrm{Xu}$ et al.'s (2013) findings will generalize to different decision scenarios, and particularly to those that are highly self-relevant and anxiety provoking, such as the dilemma described in the first paragraph. High trait anxiety has been related to increased risk appraisal for self-relevant negative events (e.g., social failure) and decreased risk appraisal for self-relevant positive events (Butler, 1987; Stöber, 1997). Xu et al. (2013) did not find a relationship between trait anxiety and overall risk avoidance, possibly because they examined relatively abstract (economic) decisions that were unlikely to be of high emotional significance to the participants. Thus, one important objective for future studies is to assess the relationship between trait anxiety, risk aversion, and the framing effect in more personally significant and emotion-evoking situations. Other relevant questions that remain to be explored are whether framing biases in anx- ious individuals within nonclinical populations are representative of those in patients with anxiety disorders, and whether other negative affective states (e.g., sadness) and disorders (e.g., depression) are associated with similar decision-making biases. Overall, Xu et al. (2013) present important evidence regarding the neural substrates of framing-related decision biases as a function of trait anxiety. Their work will hopefully inspire future research to further unravel the neural and psychological mechanisms underlying individual differences in emotional decision making.

\section{References}

Bishop SJ (2007) Neurocognitive mechanisms of anxiety: an integrative account. Trends Cogn Sci 11:307-316. CrossRef Medline

Butler G, Mathews A (1987) Anticipatory anxiety and risk perception. Cogn Ther Res 11: 551-565. CrossRef

Crittenden MR, Cottam B, Savage T, Nguyen C, Newell P, Gough MJ (2012) Expression of NF-kappaB p50 in tumor stroma limits the control of tumors by radiation therapy. PLoS One 7:e39295. CrossRef Medline

De Martino B, Kumaran D, Seymour B, Dolan RJ (2006) Frames, biases, and rational decisionmaking in the human brain. Science 313:684687. CrossRef Medline

Etkin A, Wager TD (2007) Functional neuroimaging of anxiety: a meta-analysis of emotional processing in PTSD, social anxiety disorder, and specific phobia. Am J Psychiatry 164: 1476-1488. CrossRef Medline

Hartley CA, Phelps EA (2012) Anxiety and decision-making. Biol Psychiatry 72:113-118. CrossRef Medline

Lauriola ML, I.P (2001) Personality traits and risky decision-making in a controlled experimental task: an exploratory study. Person Individ Diff 31:11. CrossRef

Power JD, Petersen SE (2013) Control-related systems in the human brain. Curr Opin Neurobiol 23:223-228. CrossRef

Roiser JP, de Martino B, Tan GC, Kumaran D, Seymour B, Wood NW, Dolan RJ (2009) A genetically mediated bias in decision making driven by failure of amygdala control. J Neurosci 29:5985-5991. CrossRef Medline

Stöber J (1997) Trait anxiety and pessimistic appraisal of risk and chance. Person Individ Diff 22:12.

Story GW, Vlaev I, Seymour B, Winston JS, Darzi A, Dolan RJ (2013) Dread and the disvalue of future pain. PLoS Comput Biol 9:e1003335. CrossRef Medline

Tversky A, Kahneman D (1981) The framing of decisions and the psychology of choice. Science 211:453-458. CrossRef Medline

Wager TD, Davidson ML, Hughes BL, Lindquist MA, Ochsner KN (2008) Prefrontal-subcortical pathways mediating successful emotion regulation. Neuron 59:1037-1050. CrossRef Medline

Xu P, Gu R, Broster LS, Wu R, Van Dam NT, Jiang Y, Fan J, Luo YJ (2013) Neural basis of emotional decision making in trait anxiety. J Neurosci 33:18641-18653. CrossRef Medline 